\title{
Sistema cannabinoide endógeno: ligandos y receptores acoplados a mecanismos de transducción de señales
}

\author{
Ramos Atance, J.A.; Fernández Ruiz, J. \\ Instituto Universitario de Drogodependencias, Departamento de Bioquímica y Biología Molecular, \\ acultad de Medicina, Universidad Complutense.
}

Enviar correspondencia a: J.A. Ramos Atance. Departamento de Bioquímica, Facultad de Medicina. Universidad Complutense, 28040-Madrid Tel.: 91-3941454 Fax: 91-3941691 e-mail: jara@eucmax.sim.ucm.es

\section{Resumen}

Numerosos estudios realizados en las dos últimas décadas han demostrado la existencia en el organismo animal de un sistema cannabinoide endógeno, constituido por unos ligandos, los endocannabinoides. Se han descrito dos tipos de receptores para cannabinoides: los denominados $\mathrm{CB}_{1}$, localizados preferentemente en cerebro y los $\mathrm{CB}_{2}$ que están localizados en el sistema inmune. Los dos endocannabinoides de los que más datos se dispone son la araquidoniletanolamida o anandamida y el 2-araquidonilglicerol, habiéndose postulado su posible actuación como neurotransmisores o neuromoduladores.

La distribución cerebral de los endocannabinoides y de los receptores $\mathrm{CB}_{1}$ ha permitido conocer las funciones fisiológicas en las que está involucrado este sistema. Participa, a través de modular la actividad de los neurotransmisores, en la regulación del comportamiento motor y de la secreción de hormonas adenohipofisarias, interacciona con la dopamina y con el GABA, mientras que, en el caso de la memoria y el aprendizaje, lo hace con el GABA y el glutamato. La dopamina y los péptidos opioides podrían estar implicados en la participación de los endocannabinoides en el sistema de recompensa y en el control de la nocicepción. Por otro lado, la síntesis de anandamida, en condiciones de isquemia, podría jugar un papel protector en las regiones cerebrales afectadas. Se ha visto que este compuesto inhibe la captación mitocondrial de calcio y la liberación de glutamato, efectos ámbos que contribuyen a la citotoxicidad cerebral.

Palabras clave: Endocannabinoides, anandamida, receptores $C B_{1}$ y $C B_{2}$, transducción de señales, neurotransmisores, cannabis.

\section{Summary}

Numerous studies carried out in the last two decades have shown the existence in the animal organism of an endogenous cannabinoide system comprising certain ligands, the endocannabinoides. Two types of receptors for cannabinoides have been described, those known as CB1, located predominantly in the brain, and the CB2 located in the immune system. The two endocannabinoides on which there is more available data are the arachidonylethanolamide or anandamide and the 2-arachidonylglycerol, their possible action as neurotransmitters or neuromodulators having been postulated.

The cerebral distribution of the endocannabinoides and the CB1 receptors has led to knowledge of the physiological functions that involve this system. It participates by modulating the action of the neurotransmitters, in regulating motor behaviour and the secretion of adenohypophysary hormones, interacts with dopamine and the GABA and, in the case of memory and learning, it interacts with the GABA and the glutamate. The dopamine and the opioid peptides may be implicated in the participation of the endocannabinoides in the drug reward system and in the control of nociception. At the same time, the synthesis of anandamine in ischemia may play a protective role in the cerebral regions affected. It has been seen that this compound inhibits the mitochondrial uptake of calcium and the liberation of glutamate, both effects that contribute to cerebral cytoxicity.

Key words: cannabis, endocannabinoids, anandamide, receptor, neurotransmitters, neuromodulators. 


\section{INTRODUCCIÓN.}

E primer paso importante en el conocimiento de la actuación de los cannabinoides sobre el cerebro se produjo en 1964 cuando se determinó la estructura del $\Delta^{9}$ - tetrahidrocannabinol (THC), principal responsable de las propiedades psicoactivas de los cannabinoides (Gaoni y Mechoulam, 1964). Este conocimiento fue completado por la caracterización de los otros cannabinoides que en mayor proporción aparecían en la planta. La búsqueda de compuestos con capacidad terapéutica condujo al desarrollo de derivados de los cannabinoides naturales. La síntesis de nuevas moléculas con características estructurales bien definidas, contribuyo a la identificación de los mecanismos de actuación de los cannabinoides.

Una vez conocida la estructura del THC, había que identificar en que zonas del cerebro actuaba para producir sus efectos y a través de que mecanismos se producían estos efectos. En el caso de los cannabinoides, esta segunda etapa comenzó con la caracterización farmacológica (Devane y cols., 1988) y mediante técnicas de biología molecular (Matsuda y cols., 1990) de un receptor cerebral para cannabinoides que se denominó $\mathrm{CB}_{1}$. Además, su distribución cerebral podía explicar las propiedades farmacológicas atribuidas a los cannabinoides.

Posteriormente, se caracterizó un segundo subtipo del receptor para cannabinoides denominado $\mathrm{CB}_{2}$, que parece estar relacionado principalmente con el sistema inmune (Munro y cols., 1993). El conocimiento de la estructura de ambos subtipos permitió el diseño de una serie de agonistas y de antagonistas que sirvieron para conocer mejor el mecanismo de actuación de estos receptores y las funciones en las que participaban los cannabinoides naturales.

En 1992, se caracterizó el primer agonista endógeno para este receptor, que recibió el nombre de anandamida (Devane y cols., 1992). Actualmente nos encontramos en la etapa de determinar cuantos agonistas endó- genos hay en el organismo, que propiedades tienen y como actúan sobre los receptores de cannabinoides ya caracterizados. También se está empezando a describir sus interacciones con sistemas de neurotransmisores concretos para así poder conocer su participación en la funcionalidad del cuerpo humano.

\section{MECANISMOS DE ACTUACIÓN DE LOS CANNABINOIDES.}

Dadas las propiedades hidrófobas de los cannabinoides, durante algún tiempo existió la idea de que su actuación sobre el organismo podría estar relacionada con una interacción con los componentes lipídicos de la célula. Los efectos podrían ser similares a los atribuidos en la década de los setenta a algunos anestésicos, como por ejemplo desorganización de la fase lipídica con un aumento en la fluidez de la membrana plasmática. El mejor conocimiento de la estructura de estos compuestos demostró posteriormente que este tipo de actuación solo podía justificar una pequeña parte de los efectos producidos por estos compuestos. El descubrimiento de los receptores para cannabinoides permitió comprobar que las acciones mejor conocidas del THC sobre el organismo son mediadas por alguno de los dos tipos de receptores actualmente conocidos y que han sido denominados $\mathrm{CB}_{1}$ y $\mathrm{CB}_{2}$.

El receptor $\mathrm{CB}_{1}$ fue caracterizado farmacologicamente utilizando el cannabinoide sintético (-)-CP-55.940. Este receptor media los efectos psicoactivos de los cannabinoides (Devane y cols., 1988). La clonación de su gen en corteza cerebral de rata, permitió la caracterización de un polipéptido de 476 aminoácidos. Se trata de un miembro de la superfamilia de receptores acoplados a proteínas $\mathrm{G}$ que se inserta en la membrana plasmática, donde se une tanto al THC como a los cannabinoides endógenos (Matsuda y cols., 1990). Este receptor está presente a lo largo de toda la escala vertebrada, con un 
patrón de distribución que se ha conservado a lo largo de la evolución. En humanos, su gen se encuentra en la región q14-q15 del cromosoma 6 , presentando una homología del $97,3 \%$ con el de rata (Hoehe y cols., 1991).

El receptor $\mathrm{CB}_{1}$ ha sido localizado en varias regiones del sistema nervioso central (hipocampo, corteza, ganglios basales, cerebelo, hipotálamo...), en terminales nerviosas periféricas y en los testículos (Herkenham y cols., 1991). Su abundancia en los ganglios basales, cerebelo e hipocampo, explica los efectos de los cannabinoides sobre la actividad motora y la memoria. Otros efectos, como los producidos sobre la regulación neuroendocrina y el control nociceptivo tienen que ver con receptores localizados en el hipotálamo y en el tallo cerebral y médula espinal, respectivamente.

El receptor $\mathrm{CB}_{2}$, aislado de bazo de rata y de una línea leucémica humana (HL60), es un polipéptido de 360 aminoácidos, que también es miembro de la superfamilia de receptores acoplados a proteínas G (Munro y cols., 1993). Ha sido localizado en células mieloides, macrófagos y monocitos de bazo, en zonas externas del bazo y en otras zonas rela- cionadas con el sistema inmune. Algunos autores han indicado su presencia en neuronas y astrocitos (Skaper y cols., 1996a; Sagan y cols., 1999). Este receptor podría participar en el mecanismo por el que los cannabinoides interaccionan con el sistema inmune, produciendo el efecto inmunosupresor que los caracteriza.

No se excluye la existencia de otros subtipos de receptores para cannabinoides que pudieran explicar algunos de los efectos producidos por estos compuestos y para los que todavía no se ha encontrado una explicación a nivel molecular (Pertwee, 1999). Por otro lado, se ha aislado un ARNm para el receptor $\mathrm{CB}_{1}$, que parece proceder del procesamiento alternativo de su transcrito primario. El receptor resultante contiene 61 aminoácidos menos que el $C B_{1}$ y se ha denominado $C B_{1} A$ (Shire y cols., 1995).

Los receptores $\mathrm{CB}_{1}$ y $\mathrm{CB}_{2}$ poseen una afinidad muy parecida por el THC y por el CP55,940, mientras que el WIN-55,212-2 posee mayor afinidad por el $\mathrm{CB}_{2}$ que por el $\mathrm{CB}_{1}$ (Felder y Glass, 1998). El receptor $C_{1}$ puede modificar la actuación de los canales iónicos para calcio y para potasio, mientras que el $\mathrm{CB}_{2}$ no parece poder hacerlo (ver Tabla 1).

\begin{tabular}{|c|c|c|}
\hline & receptores $\mathrm{CB}_{1}$ & receptores $\mathrm{CB}_{2}$ \\
\hline Localización & $\begin{array}{l}\text { sistema nervioso central } \\
\text { terminales nerviosos periféricos } \\
\text { testículos }\end{array}$ & células del sistema inmune \\
\hline Ligandos endógenos & $\begin{array}{l}\text { araquidoniletanolamida (anandamida) } \\
\text { homo-- linoleniletanolamida } \\
\text { 7,10,13,16-docosatatreniletanolamida } \\
\text { 2-araquidonil-glicerol }\end{array}$ & 2-araquidonil-glicerol \\
\hline Otros agonistas & $\begin{array}{l}\text { Cannabinoides tricíclicos y bicíclicos: } \\
\Delta^{9} \text {-tetrahidrocannabinol } \\
\text { cannabinol, cannabidiol } \\
\text { CP-55,940, desacetil-levonantradol } \\
\text { Aminoalquilindoles: } \\
\text { WIN-55,212 }\end{array}$ & $\begin{array}{l}\text { similares al CB1 pero algunas diferencias } \\
\text { en la relación estructura-actividad }\end{array}$ \\
\hline Antagonistas & $\begin{array}{l}\text { SR141716 } \\
\text { AM630 } \\
\text { AM251 } \\
\text { LY320135 }\end{array}$ & SR144528 \\
\hline Mecanismo intracelular & $\begin{array}{l}\text { inhibición de adenilato ciclasa } \\
\text { inhibición de canales de Ca++ tipo- } \mathrm{N} \\
\text { inducción de genes de transcripción temprana }\end{array}$ & $\begin{array}{l}\text { inhibición de adenilato ciclasa } \\
\text { inducción de genes de transcripción temprana }\end{array}$ \\
\hline
\end{tabular}


Los receptores $\mathrm{CB}_{1}$ aparecen en etapas tempranas del desarrollo presentando en el cerebro de rata una distribución transitoria, que va variando durante el periodo de maduración hasta alcanzar el perfil clásico del estado adulto (Berrendero y cols., 1998). La naturaleza transitoria de este fenómeno podría estar relacionada con eventos del desarrollo como la proliferación y la migración celular, la elongación axonal y la sinaptogénesis (Fernández-Ruiz y cols., 2000).

En el cerebro adulto, diversas circunstancias fisiológicas pueden alterar la densidad de estos receptores. Así, la exposición crónica a cannabinoides produce un fenómeno de desensibilización, lo que sugiere que la aparición de tolerancia para alguno de los efectos producidos por estos compuestos puede deberse a una disminución del número de receptores $\mathrm{CB}_{1}$ (Rodríguez y cols., 1994a; Romero y cols., 1997). El fenómeno de desensibilización no es igual en todo el cerebro, existiendo regiones particularmente sensibles al tratamiento crónico con cannabinoides, como el hipocampo, y regiones más resistentes, como el hipotálamo y algunas estructuras de los ganglios basales (Romero y cols., 1997).

Los receptores $\mathrm{CB}_{1}$ también son afectados por la variación de las hormonas sexuales que se produce durante el ciclo ovárico (Rodríguez y cols., 1994b). Los glucocorticoides también inhiben la expresión del receptor $\mathrm{CB}_{1}$ en cerebro de rata, lo que en situaciones de estrés podría conducir a una alteración de la funcionalidad cannabimimética (Mailleux y Vanderhaegen, 1993).

La edad puede influir en la expresión de los genes que codifican estos receptores así como sobre su funcionalidad. En el envejecimiento, se ha observado una disminución tanto de los niveles de ARNm para el receptor $\mathrm{CB}_{1}$ como de la densidad y de la afinidad de este receptor por sus agonistas en el estriado de rata (Romero y cols., 1998). Es el envejecimiento cerebral y no el desarrollo de la patología, el responsable de la disminución en el número de estos receptores en hipocampo, caudado, sustancia negra y globo pálido, tal y como ha sido descrito en estu- dios postmortem realizados con pacientes afectados por la enfermedad de Alzheimer (Westlake y cols., 1994).

La síntesis en 1994 de un antagonista para el receptor $C_{1}$ y en 1998 para el $C_{2}$ abrió una nueva página en la investigación sobre estos receptores (ver Tabla 1). EI SR141716A antagoniza algunos efectos producidos por los agonistas para el $\mathrm{CB}_{1}$, como la inhibición de la adenilato ciclasa, la hipotermia, la inmovilidad en el test del anillo o la antinocicepción (Rinaldi-Carmona y cols., 1994). El SR144528 antagoniza diversos efectos producidos por el CP-55,940 sobre el receptor $\mathrm{CB}_{2}$, entre los que se encuentra la inhibición de la producción de $\mathrm{AMP}_{\mathrm{c}}$ y la activación de la proteina-quinasa activada por mitógenos (MAPK) (Rinaldi-Carmona y cols., 1998).

Los estudios realizados con estos antagonistas han contribuido a una mejor caracterización farmacológica del correspondiente receptor y han servido para confirmar la participación de los cannabinoides en determinadas actividades cerebrales, cuando éstas son suprimidas tras la administración del antagonista. El SR141716A, administrado tras un tratamiento crónico con alguno de los agonistas del receptor $\mathrm{CB}_{1}$, da lugar a la aparición de ciertos síntomas de abstinencia (Tsou, Patrick y Walker, 1995; Aceto y cols., 1995). Estos trabajos abrieron la puerta a estudios posteriores sobre la caracterización de los mecanismos de dependencia física puestos de manifiesto tras su retirada y que serán tratados en otro capitulo de este libro.

Tanto el receptor $\mathrm{CB}_{1}$ como el $\mathrm{CB}_{2}$ están acoplados a la adenilato ciclasa por una proteína Gi, por lo que la actuación de los cannabinoides suele conducir a una disminución de los niveles de AMP (Devane y cols., 1988). En algunos casos, se ha visto que los agonistas endógenos del receptor de cannabinoides estimulan la formación de $\mathrm{AMP}_{\mathrm{c}}$, posiblemente activando proteínas Gs. La explicación de esta "paradoja" puede radicar en la existencia de varios tipos diferentes de adenilato ciclasas. Se ha descrito que los receptores $\mathrm{CB}_{1}$ y $\mathrm{CB}_{2}$ inhiben la actividad de las adenilato ciclasas I, V, VI y VIII y estimulan las II, IV y VII 
(Rhee y cols., 1998). Las isoformas I y VIII están por todo el cerebro, lo que explicaría la actividad inhibidora de los cannabinoides. Las isoformas II y VII aparecen en estriado y la II en globo pálido, lo que podría explicar algunos de los efectos activadores encontrados en ambas regiones (Maneuf y Brochie, 1997).

En relación con el efecto inhibidor de la adenilato ciclasa, dado que una de las funciones del $\mathrm{AMP}_{\mathrm{c}}$ es activar algunas quinasas, la caída de sus niveles disminuirá la fosforilación de los substratos de estas enzimas. Este es el caso de algunos canales de $\mathrm{K}^{+}$, en los que la pérdida de actividad de la proteínaquinasa dependiente de $\mathrm{AMP}_{c}$, conduce a una disminución de su fosforilación y produce un aumento de la conductancia (Deadwyler, Hampson y Childers, 1995). Esto disminuye la despolarización de la membrana y reduce la liberación del neurotransmisor presente en la terminal presináptica (Deadwyler, Hampson y Childers 1995).

Quinasas dependientes de $\mathrm{AMP}_{\text {c también }}$ participan en la modificación de la expresión genética. En el caso de los cannabinoides algunos datos obtenidos en cerebro de rata indicaban su actuación sobre algunos factores de transcripción que regulan la expresión del ARNm para determinadas proteínas (cFos, Zip-268, c-Jun) (Mailleux y cols., 1994). Otros datos más recientes muestran en células de bazo y en timocitos que la disminución de los niveles de AMP c producidos por la actuación de los cannabinoides inhibe la unión al ADN de tres tipos de familias de factores de transcripción nucleares, CREB/ATF, AP-1 (fos-jun) y NF-kB/rel, los cuales están implicados en la regulación de varios genes, entre los que se encuentran los de algunas citoquinas (Kaminski, 1998).

La reciente descripción de un efecto activador de los cannabinoides sobre las adenilato ciclasas tipo II, IV y VII sirve como justificación del efecto activador del CP-55,940 sobre el factor de transcripción CREB, lo que había entrado en colisión con la idea previamente aceptada de que la activación del receptor $\mathrm{CB}_{1}$ implicaba una inhibición de los factores de transcripción activados vía proteína quina-
sa-A (Calandra y cols., 1999). Además, se postula que la existencia de efectos activadores e inhibidores de la adenilato ciclasa podría ser el ejemplo de un tipo de acoplamiento dual cuyo resultado final dependería del balance entre ambos tipos de estímulos.

Desde el punto de vista del consumo de cannabinoides, la utilización por estos compuestos de los mecanismos de transcripción celular puede producir una modificación de la expresión genética, que si persiste durante un periodo prolongado de tiempo, puede conducir a una "cronificación" de determinadas actividades metabólicas no existentes previamente al consumo de estas sustancias.

Los cannabinoides también actúan sobre los canales de $\mathrm{Ca}^{++}$del tipo N (Mackie y Hille,

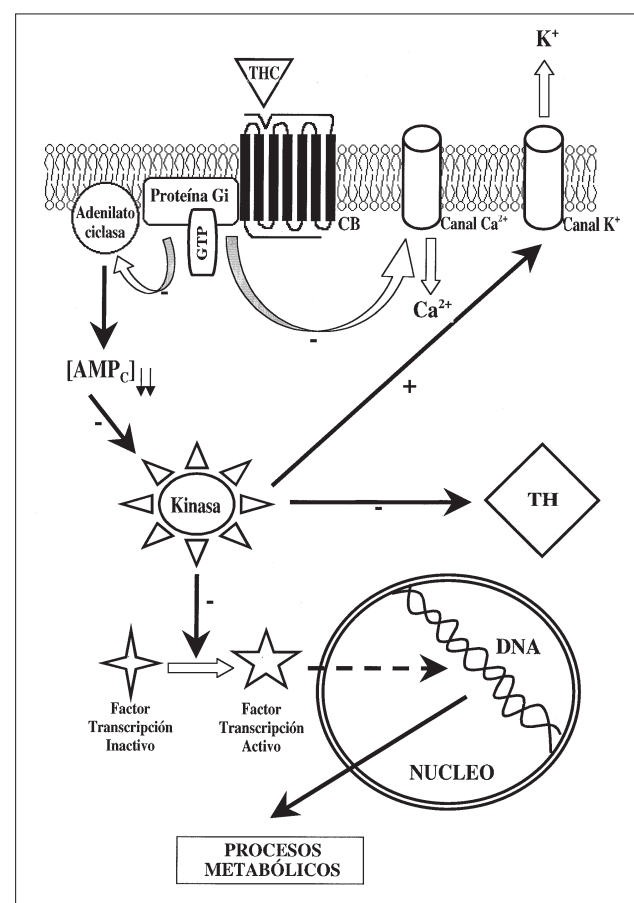

Figura 1. Mecanismo de actuación del receptor $\mathrm{CB}_{\text {, }}$

1992) y del tipo P/Q (Twichell, Brown y Mackie, 1997). El mecanismo de actuación parece implicar a los receptores $C_{1}$ y es independiente del metabolismo del $\mathrm{AMP}_{\mathrm{c}}$. El resultado es la inhibición de la entrada de cal- 
cio a la neurona, lo que origina en el terminal presináptico una disminución de la liberación de neurotransmisores como la norepinefrina, el glutamato o la acetilcolina. El receptor $\mathrm{CB}_{1}$ puede inactivarse por fosforilación. Se ha visto que, cuando es fosforilado en su serina 317 por la proteina-quinasa $\mathrm{C}$, pierde su capacidad de activar los canales de $\mathrm{K}^{+} \mathrm{y}$ de inhibir los de $\mathrm{Ca}^{++}$(García y cols., 1998). Este mecanismo de fosforilación podría ser utilizado por las neuronas para revertir la inhibición producida por los cannabinoides sobre la liberación de neurotransmisores.

Los cannabinoides pueden activar la fosfolipasa $A_{2}$, cuya actuación conduce a la liberación de ácido araquidónico. Este ácido graso puede ser utilizado para la formación de diversos eicosanoides, como las prostaglandinas y los leucotrienos. Los eicosanoides son sustancias que producen diversos efectos sobre la función cerebral. Entre ellos se encuentra, la alteración en la percepción del tiempo, el aumento del ritmo cardíaco y el "high" subjetivo que aparece en humanos tras el consumo de cannabis (Pérez-Reyes y cols., 1991). Uno de los mecanismos implicados en la activación de la fosfolipasa $A_{2}$ está relacionado con un aumento de la actividad de la denominada vía de las MAP quinasas (MAPKs) (Wartmann y cols., 1995). Estas proteínas son activadas por mitógenos y producen la fosforilación de diversos substratos biológicos. Los cannabinoides activan las MAPKs por un mecanismo que requiere la actuación del receptor $\mathrm{CB}_{1}$, pero que es independiente de la adenilato ciclasa. Algunos mitógenos, como la insulina y el factor de crecimiento similar a insulina I, participan en esta vía, dado que el SR144528 inhibe la activación de las MAPKs producida por estos factores (Bouaboula y cols., 1997). No se ha aclarado todavía como se produce la conexión entre el receptor $\mathrm{CB}_{1}$ y las MAPKs, aunque se ha indicado que la actuación de los cannabinoides sobre su receptor podría implicar la hidrólisis de esfingomielinas. La ceramida producida en esta reacción podría activar la vía de las MAPKs mediante la estimulación de las Raf-1 (Guzmán y Sánchez, 1999).
También el receptor $\mathrm{CB}_{2}$ utiliza la vía de las MAPKs, aunque para ello parece ser necesaria también la activación de la proteína-quinasa C (Bouaboula y cols., 1996). Se ha descrito que los cannabinoides producen, a través de esta vía, un aumento de la expresión del gen relacionado con el crecimiento Krox-24. Este efecto se produce tanto con el receptor $\mathrm{CB}_{1}$ (Bouaboula y cols., 1995) como con el $\mathrm{CB}_{2}$ (Bouaboula y cols., 1996).

El que la activación de la vía de las MAPKs por el receptor $\mathrm{CB}_{2}$ requiera de la activación de la proteína-quinasa $\mathrm{C}$, puede estar relacionado con la participación de los cannabinoides en la movilización del $\mathrm{Ca}^{++}$intracelular. Su actuación, vía una proteína GP, activa la fosfolipasa C. Esta enzima produce IP3, que conduce a la liberación de $\mathrm{Ca}^{++}$del retículo endoplásmico, y diacilglicerol, que activa la proteína-quinasa C. Los cannabinoides activan esta última proteína por un mecanismo que podría alterar la disposición normal de los lípidos de la membrana celular. El THC facilitaría la inserción de la enzima en el dominio hidrófobo de la membrana al disminuir la cantidad de $\mathrm{Ca}^{++}$necesario para promover su asociación con ésta (Hillard y Aucharmpach, 1994).

\section{LIGANDOS ENDÓGENOS DEL RECEP- TOR DE CANNABINOIDES.}

La existencia de receptores para cannabinoides en el organismo humano hacía sospechar la existencia de algún compuesto endógeno que pudiera actuar sobre ellos. Las investigaciones realizadas sobre el tema dieron su fruto en 1992, año en que se publicó la caracterización, a partir de cerebro de cerdo, del primer cannabinoide endógeno conocido, al que se dio el nombre de anandamida. Este compuesto está formado por ácido araquidónico unido por un enlace amida a etanolamina (Devane y cols., 1992).

La anandamida ha sido identificada en cerebro y en tejidos periféricos humanos y de rata. En ambas especies se ha detectado 
en hipocampo, estriado y cerebelo, regiones ricas en receptores $\mathrm{CB}_{1}$, así como en tálamo, donde la expresión de este receptor es mucho más baja. También esta presente en bazo, donde hay altos niveles del receptor $\mathrm{CB}_{2}$. Hay pequeñas cantidades de anandamida en corazón humano y en piel de rata y aparece en trazas en suero, plasma y líquido cefalorraquídeo humanos (Felder y Glass, 1998). La anandamida aumenta su concentración a lo largo del desarrollo en el cerebro de rata (Berrendero y cols., 1999).

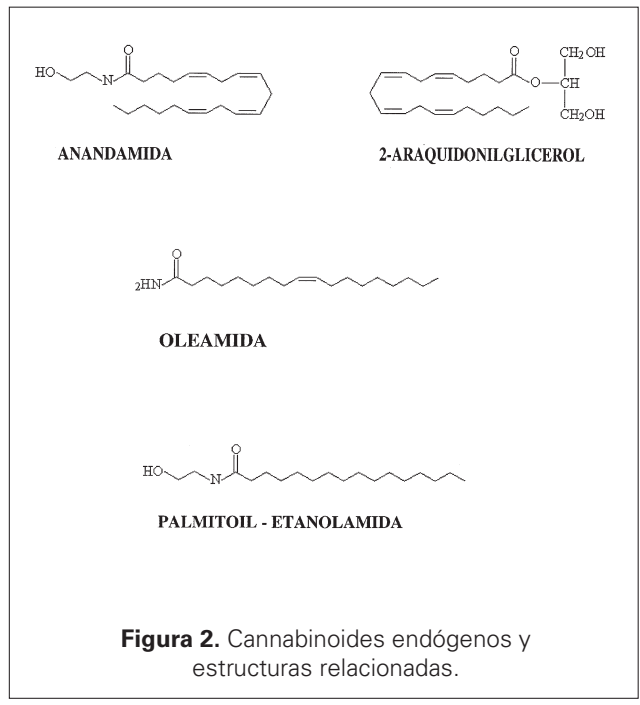

Posteriormente, se caracterizaron otros cannabinoides endógenos. Dos de ellos, la homo--linoleiletanolamida y la 7,10,13,16 docosatetraeniletanolamida, también contienen etanolamina unida a los ácidos grasos insaturados homo--linoleico y 7,10,13,16 docosatetraenoico, respectivamente (Hanus y cols., 1993). El tercero, el 2-araquidonilglicerol, está formado por ácido araquidónico unido por un enlace ester a glicerol. El 2-araquidonilglicerol fue aislado inicialmente en intestino de perro y posteriormente en bazo y páncreas, lo que hizo pensar que se trataba de un ligando periférico (Mechoulam y cols., 1995; Martin y cols., 1999). Más tarde fue identificado en cerebro, donde está presente a concentraciones bastante más altas que las de anandamida (Sugiura y cols., 1995). Su distribución en cerebro adulto presenta las máximas concentraciones en tronco cerebral, estriado e hipocampo y las más bajas en corteza, diencéfalo y cerebelo (Bisogno y cols., 1999).

Como puede verse en la tabla 2, los endocannabinoides no siempre presentan el mismo patrón de distribución en el cerebro que los receptores $\mathrm{CB}_{1}$ (Bisogno y cols., 1999). Existen regiones como la médula espinal y el tallo cerebral, donde hay niveles relativamente altos de endocannabinoides pero con una baja densidad de receptores $\mathrm{CB}_{1}$, o el cerebelo, donde la densidad de receptores es alta pero los niveles de endocannabinoides bajos. Estas diferencias podrían estar relacionadas con la existencia de algún endocannabinoide todavía no caracterizado o con diferencias en la eficacia de la activación de los receptores según regiones, como ha sido, por ejemplo, indicado para el hipotálamo (Breivogel y cols., 1997).

Estos cuatro endocannabinoides producen en ratón los mismos efectos que el THC: antinocicepción, inmovilidad (e incluso catalepsia), reducción de la actividad espontánea e hipotermia. Sin embargo, la intensidad es inferior a la producida por el THC, lo que indica que podrían actuar como agonistas parciales del receptor.

Previamente al aislamiento de la anandamida ya se disponía de información sobre la presencia en animales superiores de otras amidas con estructuras parecidas. Este era el caso de la palmitoiletanolamida, formada por la unión del ácido palmítico con etanolamina, cuya presencia fue descrita en cerebro, hígado y músculo esquelético de ratas en ayunas (Bachur y cols., 1995). Posteriormente, se ha visto su relación con la inflamación y con la actividad del sistema inmune (Facci y cols, 1995), con la analgesia (Calignano y cols., 1998) y con la neuroprotección (Skaper y cols., 1996b). Dado que esta amida saturada no parece tener una afinidad apreciable por el receptor $\mathrm{CB}_{1}$ ni por el $\mathrm{CB}_{2}$ se la ha relacionado con otro tipo de receptor aún no conocido (Calignano y cols., 1998). 


\begin{tabular}{|lccc|}
\hline \multicolumn{4}{|c|}{ Tabla 2. Localización de los endocannabinoides y de los receptores $\mathbf{C B}_{\mathbf{1}}$} \\
en diversas regiones cerebrales.
\end{tabular}

Otras amidas presentes en animales superiores y en humanos son amidas primarias formadas por un ácido graso insaturado y amoniaco. Una de ellas es la erucamida (13cis-docosenamida), que fue aislada de mesenterio bovino. Este compuesto, en el que el ácido graso es el 13-cisdocosenoico, parece tener propiedades angiogénicas (Wakamatsu y cols., 1990). Otra es la oleamida, en la que el ácido graso es el ácido oleico. Esta amida aparece en líquido cefalorraquídeo de gatos, ratas y humanos. Actúa potenciando la acción de la serotonina sobre sus receptores $5 \mathrm{HT}_{2 \mathrm{~A}}$ y $5 \mathrm{HT}_{1 \mathrm{c}}$, lo que produce en ratas alguna de las características del sueño como enlentecimiento motor, cierre de los ojos, comportamiento sedado y una respuesta peculiar a diversos estímulos auditivos (Cravat y cols., 1996). La oleamida podría formar parte de un sistema cannabinoide endógeno relacionado con la regulación del ciclo "sueño-vigilia". Se sabe que la intoxicación con marihuana produce modorra y somnolencia. También se ha visto que el SR141716A aumenta el tiempo que se permanece despierto a costa tanto del sueño de "onda lenta" como del de "movimiento rápido de ojos". La observación de que la oleamida inhibe la anandamida hidrolasa sería un dato a favor de esta hipótesis, dado que se prolongaría la actuación de la anandamida.

\section{MECANISMOS DE ACTUACIÓN DE LOS ENDOCANNABINOIDES.}

La unión de la anandamida a los receptores $C_{1}$ o $C_{2}$ inhibe la formación de $A M P_{c} y$ activa la vía de transducción de señales de las MAPKs. Unicamente su unión al receptor $\mathrm{CB}_{1}$ inhibe los canales de $\mathrm{Ca}^{++}$tipo N (Pertwee, 1997). También se ha indicado que la unión de la anandamida al receptor de cannabinoides está acoplada a la liberación de óxido nítrico en el sistema nervioso central de invertebrados y en las células del sistema inmune de invertebrados y de humanos (Stefano, Liu y Goligorsky, 1996).

La anandamida, al igual que ocurría con el THC, estimula la liberación intracelular de ácido araquidónico a través de mecanismos que implican un aumento de la actividad de las MAPKs y de la fosforilación de una fosfolipasa A2 citoplasmática (Wartmann y cols., 1995). Se ha visto que la anandamida aumenta en hipocampo y en cerebro anterior de rata la fosforilación de la quinasa de adhesión focal pp125 (FAK+) (Derkinderen y cols., 1996). Esta proteína está presente en los conos de crecimiento de neuronas jóvenes por lo que podría ejercer efectos neurotróficos. También esta relacionada con la interacción entre las integrinas y el citoesqueleto asociado a actina, lo que podría implicar a la anandamida en la modifica- 
ción de la plasticidad sináptica. También se ha postulado un posible papel de la anandamida como factor de crecimiento en las células hematopoyéticas, en las que actuaría sinérgicamente con IL3 (interleukina 3), GM-CSF (factor estimulante de colonias granulocitosmacrófagos), G-CSF (factor estimulante de colonias de granulocitos) y Epo (eritropoyetina) (Valk y cols., 1997).

La exposición crónica a anandamida produce, igual que ocurría con los cannabinoides, la desensibilización del receptor $\mathrm{CB}_{1}$. Se ha descrito la aparición de tolerancia para alguno de los efectos producidos por esta amida, que puede deberse a una disminución del número de receptores CB 1 (Romero y cols., 1995).

El 2-araquidonilglicerol se une a los receptores $\mathrm{CB}_{1}$ y $\mathrm{CB}_{2}$ inhibiendo la actividad de la adenilato ciclasa. Durante su caracterización, se identificaron otros dos monoacilgliceroles, el 2-palmitoilglicerol y el 2-linoleilglicerol, ninguno de los cuales presenta afinidad por los receptores $\mathrm{CB}_{1} \circ \mathrm{CB}_{2}$, ni actividad cannabimimética. Sin embargo, ambos compuestos potencian algunos efectos producidos por el 2-araquidonilglicerol, como la inhibición de la adenilato ciclasa, la inhibición del comportamiento motor, la inmovilidad y la hipotermia (Ben-Shabat y cols., 1998). Esta activación podría deberse a su capacidad de inhibir la hidrolasa que degrada el 2-araquidonilglicerol, lo que prolongaría la permanencia de este compuesto en el organismo.

En cuanto a las posibles funciones del 2-araquidonilglicerol en el organismo, además de los efectos sobre el comportamiento motor y la regulación de la temperatura corporal, inhibe la potenciación a largo plazo en hipocampo de rata (Stella, Schweitzer y Piomelli, 1997). También parece participar en las respuestas proliferativas de los linfocitos T a los mitógenos B y T (Lee, Yang y Kaminski, 1995).

\section{SÍNTESIS Y DEGRADACIÓN DE LOS EN- DOCANNABINOIDES.}

Se ha descrito recientemente como se produce la síntesis del 2-araquidonilglicerol en las neuronas de la corteza cerebral, mediante un mecanismo activado por la entrada de $\mathrm{Ca}^{++}$a la neurona. Una diacilglicerol lipasa o la fosfolipasa $\mathrm{C}$ actúan sobre diacilglicerol, liberando una molécula de ácido graso de la posición sn 1 del glicerol. La enzima se activa al despolarizarse la membrana, vía canales de $\mathrm{Ca}^{++}$ dependientes de voltaje. Una vez cumplida su función, el compuesto es degradado a ácido araquidónico y glicerol por una monoacilglicerol lipasa cuya presencia en los tejidos cerebrales se conoce desde hace tiempo (Stella, Schweitzer y Piomelli, 1997).

El diacilglicerol puede proceder de la degradación de los fosfolípidos de membrana, tras la actuación de una fosfolipasa C. La síntesis del 2-araquidonilglicerol también puede estar asociada a otros procesos metabólicos como por ejemplo la síntesis de novo de diacilglicerol o la remodelación de los fosfolípidos.

El mecanismo más probable para la síntesis de la anandamida es el inicialmente descrito en estriado y corteza de rata (Di Marzo y cols., 1994). La anandamida se sintetiza y libera tras la entrada de $\mathrm{Ca}^{++}$al interior de la neurona. La síntesis de anandamida y de otras $\mathrm{N}$-aciletanolaminas (NAEs) se produce mediante la hidrólisis de un precursor fosfolipídico presente en la membrana celular, la Nacil-fosfatidiletanolamina (NAPE), que puede estar $\mathrm{N}$-acilada por diferentes ácidos grasos: araquidónico, g-linolénico, linoleico, oleico, palmítico o esteárico. La acción de la fosfolipasa $D$, libera ácido fosfatídico y los correspondientes tipos de NAEs. El que se formen y liberen unas u otras depende del ácido graso que forma parte de la NAPE presente en la célula estimulada.

Respecto de la síntesis de este precursor, recientemente se ha caracterizado en corteza cerebral de rata una $\mathrm{N}$-aciltransferasa (NAT), dependiente de $\mathrm{Ca}^{++}$que produce NAPE mediante la transferencia de un grupo acilo procedente de una fosfatidilcolina al grupo amino de la fosfatidiletanolamina. La reacción es estimulada por la actividad neuronal que conduce a la despolarización de la membrana. 


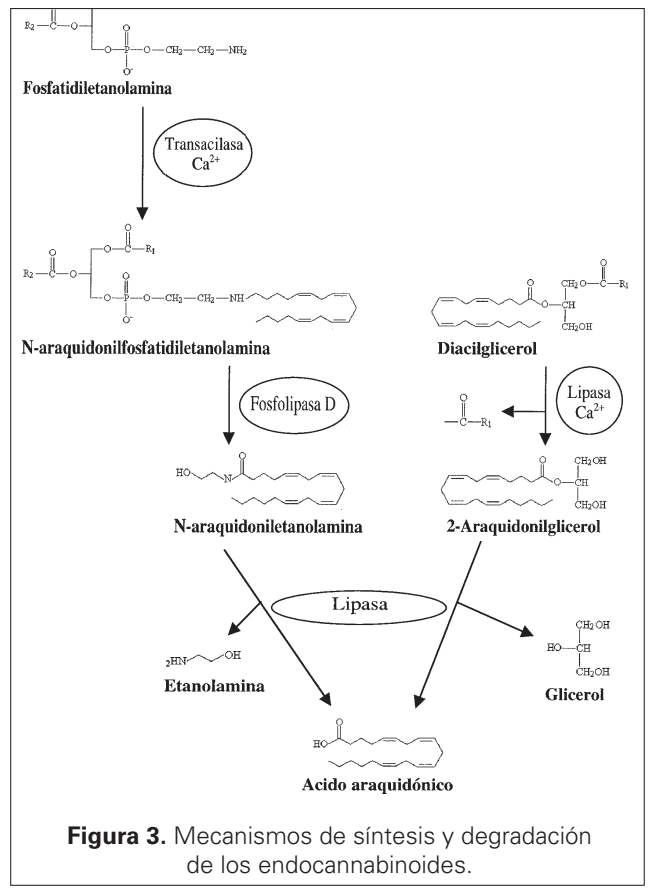

Una vez cumplida su función, la anandamida o las otras NAEs son captadas selectivamente tanto por neuronas como por células gliales, donde son degradadas a etanolamina y el correspondiente ácido graso. Este proceso de captación es mediado por un transportador específico (Beltramo y cols., 1997). El ácido araquidónico y parte de la etanolamina se suelen reincorporar a los fosfolípidos de membrana. La amidohidrolasa de ácidos grasos (FAAH) parece ser la enzima responsable de la hidrólisis de las NAEs. Su distribución en cerebro de rata es bastante parecida a la del receptor $\mathrm{CB}_{1}$. La FAAH ha sido purificada, clonada y secuenciada (Cravatt y cols., 1996). Su activación en cerebro humano podría estar acoplada a la del transportador de anandamida. La unión de la anandamida al receptor $\mathrm{CB}_{1}$ activaría la producción de óxido nítrico. Este compuesto podría activar el transportador de anandamida, lo que aumentaría la presencia de sustrato para la FAAH (Maccarrone y cols., 1998). La anandamida también puede ser metabolizada por el citocromo P-450, mediante un metabolismo

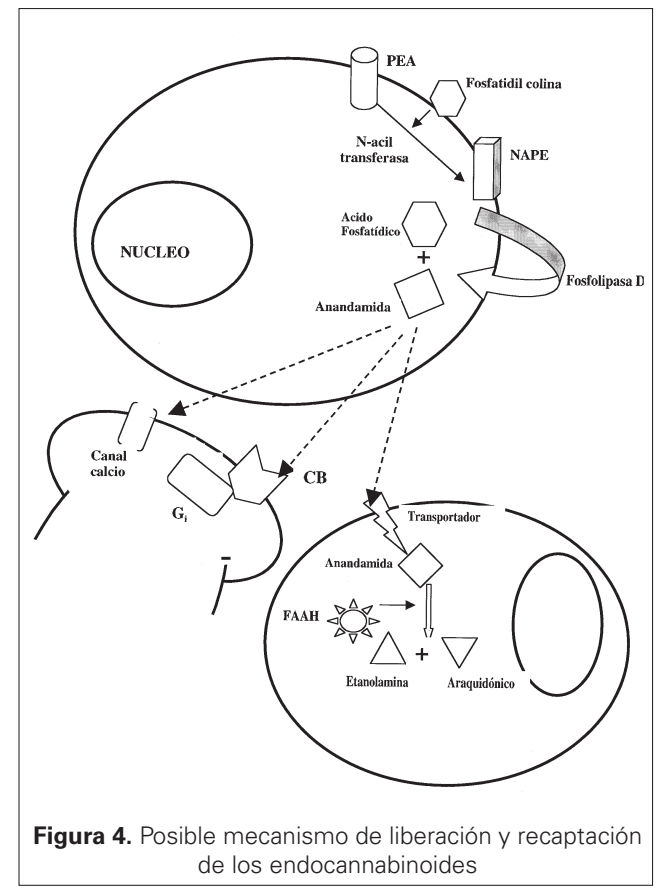

secuencial que origina productos mono- y dihidroxilados así como epóxidos (Bornheim y cols., 1995).

La existencia de NAPEs en la membrana celular había sido indicada anteriormente en diversos tipos de células y en diferentes circunstancias metabólicas. Así, en áreas infartadas de miocardio y en cerebro de perro en condiciones isquémicas, se producen N-palmitoil y N-esteariletanolamina. Se postula que el exceso de calcio, producido en estas situaciones, activaría la síntesis de NAEs. Estos compuestos inhibirían la captación mitocondrial de calcio y su acción sobre el transporte de electrones, lo que sería beneficioso para el tejido isquémico. La biosíntesis, inducida por la lesión, serviría para la protección del tejido en condiciones patológicas (Schmid, Schmid y Natarajan, 1990).

La síntesis de NAPEs y de NAEs puede estar relacionada con la citotoxicidad cerebral inducida por un exceso de ácido glutámico, cuya actuación sobre los receptores NMDA produce la entrada de calcio a la neurona. Al ser la N-acil transferasa y la fosfolipasa D dos 
enzimas dependientes de calcio, el aumento de su actividad elevaría la concentración de NAPEs y de NAEs (Hansen y cols., 1997). En relación con esta hipótesis, se ha visto que la liberación de ácido glutámico es inhibida en neuronas hipocampales de rata por la anandamida, vía receptor $\mathrm{CB}_{1}$, al impedir la entrada de $\mathrm{Ca}^{++}$en la terminal nerviosa (Shen y cols., 1996).

Cuando se estudia si los endocannabinoides se comportan como neurotransmisores se observa que la concentración de anandamida en cerebro es bastante más baja que la de los neurotransmisores clásicos. En cambio la liberación es parecida, al ser estimulada en ambos casos por la despolarización de la membrana y la entrada de calcio al interior de la neurona. Sin embargo, existen diferencias en su almacenamiento, dado que los endocannabinoides no han sido localizados en vesículas, quizás debido a su naturaleza hidrófoba. Su almacenamiento se produciría en forma de un precursor (fosfolípidos de membrana) que se acila e hidroliza posteriormente. La síntesis del compuesto se producirá cuando sea necesaria su actuación.

Las NAEs, entre las que se encuentra la anandamida, podrían ser liberadas al espacio intersináptico, por un mecanismo de difusión facilitada bidireccional, realizado a favor de gradiente (Hillard y cols., 1997). Es curioso que entre los diferentes tipos de NAEs la que contiene ácido araquidónico es una de las que aparecen en cantidades más bajas. No se conoce aún el posible significado biológico de este hecho.

Los endocannabinoides podrían ser otro tipo de intermediario metabólico lipídico, que como los eicosanoides y el factor activador de plaquetas se sintetizan por la hidrólisis de un fosfolípido, actuando cerca del sitio de producción, donde también se degradan rápidamente. Su solubilidad en lípidos les permitiría difundir libremente a través de las membranas y actuar como moduladores de diversas actividades biológicas (Felder y Glass, 1998). Algunos datos apuntan a que la anandamida podría ser un mero transportador de ácido araquidónico. Este tipo de actuación ha sido des- crito en hepatocitos, donde el ácido araquidónico, una vez degradada la anandamida que lo contiene, activa la producción de cuerpos cetónicos (Guzmán y cols., 1995).

\section{CANNABINOIDES Y ACTIVIDAD DE DI- VERSOS NEUROTRANSMISORES.}

La localización cerebral de los elementos del sistema cannabinoide endógeno (endocannabinoides y sus receptores) ha permitido conocer las funciones endógenas de los endocannabinoides así como explicar los efectos que producen los cannabinoides presentes en la Cannabis sativa. En la Tabla 3, aparecen algunos de los procesos cerebrales en los que están implicados los endocannabinoides. Su participación en estas funciones tiene que ver con su capacidad de modular la actividad de ciertos neurotransmisores clásicos que son clave en estos procesos. Lógicamente, estos neurotransmisores serían también dianas farmacológicas de los cannabinoides presentes en la marihuana o el hachís. Por lo tanto, para poder conocer las funciones normales que este sistema desarrolla en el cerebro es importante saber con que neurotransmisores interacciona el sistema cannabinoide endógeno y en que regiones se produce dicha interacción.

Se ha propuesto que los endocannabinoides podrían funcionar como neuromoduladores que servirían para reducir la liberación de ciertos neurotransmisores durante periodos de estimulación intensa. La actuación de los endocannabinoides sobre receptores presinápticos $\mathrm{CB}_{1}$ reduciría la actividad neuronal a través de la inhibición de canales de $\mathrm{Ca}^{++}$sensibles a voltaje, cuya apertura es necesaria para producir la liberación de neurotransmisor (Herkenham y cols, 1991b). Alternativamente, la activación de los receptores $\mathrm{CB}_{1}$ podría incrementar la entrada de $\mathrm{K}^{+}$, lo que reducía la intensidad de eventuales despolarizaciones, la generación de potenciales de acción y, en definitiva, la propagación del impulso nervioso. Entre los neurotransmi- 


\begin{tabular}{|c|c|}
\hline Proceso cerebral & Función atribuida a los endocannabinoides \\
\hline control de la actividad motora & los cannabinoides producen inhibición motora e incluso catalepsia. \\
\hline control del dolor & los cannabinoides tienen efectos analgésicos. \\
\hline memoria y aprendizaje & los cannabinoides producen alteraciones de la memoria a corto plazo. \\
\hline motivación y emocionalidad & los cannabinoides alteran los procesos cognitivos. \\
\hline regulación neuroendocrina & los cannabinoides modifican la secreción de hormonas adenohipofisarias. \\
\hline procesos neurovegetativos & $\begin{array}{l}\text { los cannabinoides actuan, entre otros, a nivel de los centros nerviosos } \\
\text { reguladores de la emesis, de la temperatura y del apetito. }\end{array}$ \\
\hline desarrollo cerebral & $\begin{array}{l}\text { los cannabinoides, actuando como factores epigenéticos, podrían tener } \\
\text { efectos sobre la proliferación de neuronas y/o células gliales, sobre la migra- } \\
\text { ción y elongación axonal, sobre la sinaptogénesis y/o sobre la mielinogénesis. }\end{array}$ \\
\hline
\end{tabular}

sores que interaccionan con los cannabinoides se encuentran:

(i) dopamina (DA) y otras monoaminas $(5 \mathrm{HT}$, $\mathrm{NE})$, que tiene que ver con el control de la actividad motora, el control de la secreción de hormonas adenohipofisarias y con la recompensa cerebral;

(ii) aminoácidos neurotransmisores, relacionados con el control de la actividad motora y de la secreción de hormonas adenohipofisarias (GABA), y con la memoria y el aprendizaje (GABA y glutamato);

(iii) péptidos opioides, implicados en el control de la nocicepción y con el refuerzo.

\subsection{Aminas biógenas}

Entre los neurotransmisores afectados por el consumo de marihuana en humanos o por la actividad de los endocannabinoides se encuentran la DA y la serotonina (5HT), cuyos cuerpos celulares se localizan en la formación reticular del cerebro medio y del tallo cerebral. Estas neuronas inervan estructuras del cerebro anterior compuestas por neuronas efectoras que se encargan de llevar a cabo los procesos de integración y ejecución de las respuestas comportamentales. Ambos neurotransmisores son afectados por los can- nabinoides hasta el punto que se piensa que alteraciones de la actividad de estas neuronas, sobre todo dopaminérgicas, del cerebro medio, pueden subyacer en los efectos motores, euforizantes y emocionales observados tras la exposición a la marihuana.

\subsubsection{Dopamina}

Los cannabinoides actúan sobre las neuronas dopaminérgicas mesocorticolímbicas (Gardner, 1992), que constituyen el principal componente del circuito de recompensa y sobre las neuronas dopaminérgicas nigroestriatales y tuberoinfundibulares para producir inhibición motora y cambios de la secreción de hormonas adenohipofisarias, respectivamente. Sin embargo, los receptores $C_{1} B_{1}$ no se encuentran localizados en las neuronas dopaminérgicas, sino en neuronas vecinas (normalmente GABAérgicas) (Herkenham y cols., 1991b). La existencia de una relación funcional entre ellas explicaría los cambios que se producen en la actividad dopaminérgica tras la activación de los receptores $\mathrm{CB}_{1}$. Sin embargo, durante el desarrollo cerebral, los receptores $\mathrm{CB}_{1}$ podrían expresarse de forma transitoria en neuronas dopaminérgicas (Hernández y cols., 1999), con una fun- 
ción específica en procesos relacionados con el desarrollo del cerebro (Berrendero y cols., 1998).

Aunque se ha descrito la presencia de endocannabinoides y de receptores $C_{1}$ en las áreas límbicas, no se conoce que papel juegan en la funcionalidad de las neuronas dopaminérgicas mesocorticolímbicas (Herkenham y cols., 1991a; Bisogno y cols., 1999; ver Tabla 3). Los efectos euforizantes, motivacionales y cognitivos producidos por el $\Delta^{9}$ THC parecen estar relacionados con una activación de estas neuronas. El $\Delta^{9}$-THC es capaz de potenciar la recompensa por estimulación cerebral en ratas (Gardner, 1992), incrementando la excitabilidad de las neuronas dopaminérgicas mesocorticolímbicas (French y cols., 1997), los contenidos de DA y sus metabolitos y la densidad de los receptores dopaminérgicos $D_{1}$ en varias estructuras límbicas (Navarro y cols., 1993) y la liberación de DA, medida mediante microdiálisis in vivo, en el núcleo accumbens (Chen y cols., 1990).

En relación con las neuronas dopaminérgicas niogroestriatales, tanto los cannabinoides naturales o sintéticos, como los endocannabinoides, inhiben la actividad motora, lo que coincide con la alta densidad de receptores CB 1 (Herkenham y cols., 1991a y 1991b), y los niveles altos de anandamida y 2-araquidonilglicerol (Bisogno y cols., 1999; ver Tabla 3) en los ganglios basales y en el cerebelo. En ratones, se ha observado reducción de la actividad espontánea y estereotipada, así como producción de catalepsia (Wickens y Pertwee, 1993). En ratas, se ha visto disminución de la actividad ambulatoria espontánea, atenuación de la actividad estereotipada espontánea o inducida e incremento de la inactividad (Romero y cols., 1995a, 1996a). No obstante, se han observado diferencias en la magnitud y duración de los efectos entre los cannabinoides clásicos, como el $\Delta^{9}$ THC, y los endocannabinoides, como la anandamida (Romero y cols., 1995b), que pueden ser atribuibles a sus diferencias en potencia farmacológica y estabilidad metabólica.

Los cambios observados en la actividad dopaminérgica nigroestriatal van en paralelo a

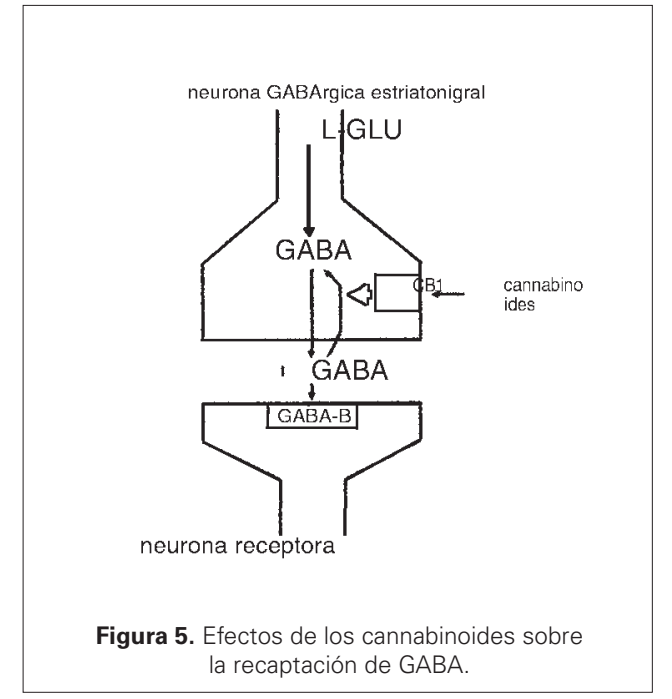

los cambios a nivel motor (Tabla 4). Así, la inhibición motora causada por la administración de anandamida se corresponde con un descenso en la actividad de la tirosina hidroxilasa (TH) en estriado. Sin embargo, la disminución de la actividad dopaminérgica nunca fué tan marcada como podía esperarse de la notable depresión motora producida (Romero y cols., 1995a y 1995b). Esto puede deberse a que las neuronas dopaminérgicas nigroestriatales no poseen receptores $\mathrm{CB}_{1}$, los cuales se localizan presinápticamente en los terminales de las neuronas estriato-eferentes que contienen GABA (Herkenham y cols., 1991b). En estas neuronas, los cannabinoides inhiben la recaptación de GABA (Maneuf y cols., 1996; Romero y cols., 1998a). Los receptores $\mathrm{CB}_{1}$ están localizados con los receptores dopaminérgicos, $D_{1}$ y $D_{2}$, (Herkenham y cols., 1991b), por lo que se ha sugerido que ambos tipos de receptores $\left(C_{1}\right.$ y dopaminérgicos) podrían interaccionar a nivel de sus mecanismos intracelulares de transducción de señales.

Mediante microdiálisis, se puede detectar liberación de anandamida en el estriado de ratas cuando se estimulan los receptores dopaminérgicos D2 (Giuffrida y cols., 1999). Esta liberación puede conducir a una inhibición del comportamiento motor. El que el 
SR141716A aumente la activación motora producida por los agonistas $D_{2}$ parece indicar que el bloqueo del receptor $\mathrm{CB}_{1}$ eliminaría la inhibición producida por el sistema cannabinoide endógeno sobre la activación dopaminérgica.

El $\Delta^{9}$-THC, y la anandamida, actúan sobre las neuronas dopaminérgicas tuberoinfundibulares, disminuyendo la secreción de prolactina (PRL) y modificando la de otras hormonas adenohipofisarias (para revisión, ver Fernández-Ruiz y cols., 1997). Estos efectos se producen en paralelo a un aumento, en el núcleo arcuado, de la actividad de la TH, enzima que regula la velocidad de síntesis de DA
(Romero y cols., 1994). Sin embargo, no parece que los receptores $\mathrm{CB}_{1}$ hipotalámicos estén situados sobre las neuronas tuberoinfundibulares dopaminérgicas. Los cuerpos celulares de las neuronas que contienen receptores $\mathrm{CB}_{1}$ se localizan en el núcleo ventromedial hipotalámico (Mailleux y Vanderhaeghen, 1992) y son intrínsecas al hipotálamo (Romero y cols., 1998b).

\subsubsection{Serotonina}

Algunos de los efectos neurocomportamentales del $\Delta^{9}$-THC han sido relacionados con alteraciones de la neurotransmisión sero-

\begin{tabular}{|c|c|}
\hline Neurotransmisor & Efectos de los cannabinoides sobre distintos indices neuroquímicos \\
\hline \multirow[t]{3}{*}{ Dopamina } & $\begin{array}{l}\text { disminución de la densidad de los receptores D1 y D2 en el estriado } \\
\text { disminución de la actividad de TH en el estriado } \\
\text { disminución de la liberación in vitro de DA en el estriado }\end{array}$ \\
\hline & $\begin{array}{l}\text { incremento de la producción de DOPAC y HVA en regiones límbicas } \\
\text { incremento de la liberación de DA en el núcleo accumbens } \\
\text { incremento de la densidad de receptores D1 en regiones límbicas }\end{array}$ \\
\hline & incremento de la actividad de la TH en el hipotálamo \\
\hline Serotonina & implicación serotoninérgica en los efectos de los cannabinoides sobre la secreción de PRL \\
\hline \multirow[t]{3}{*}{ GABA } & $\begin{array}{l}\text { antagonistas GABA-B atenuan la inhibición motora provocada por cannabinoides } \\
\text { antagonistas GABA-A son ineficaces } \\
\text { los cannabinoides no alteran la liberación de GABA en la substancia nigra } \\
\text { los cannabinoides inhiben la recaptación de GABA en la substancia nigra }\end{array}$ \\
\hline & incremento de los contenidos de GABA en el hipotálamo y en la adenohipófisis \\
\hline & $\begin{array}{l}\text { cambios en la actividad GABAérgica en el hipocampo (relación con la memoria) } \\
\text { Implicación de receptores GABA-B }\end{array}$ \\
\hline Glutamato & disminución de la liberación de glutamato en el hipocampo y en el cerebelo \\
\hline Péptidos opioides & $\begin{array}{l}\text { los cannabinoides y los opioides comparten diversos efectos farmacológicos } \\
\text { los receptores CB1 y los receptores opioides podrían interaccionar a nivel post-receptor } \\
\text { los cannabinoides incrementan la síntesis y liberación de péptidos opioides }\end{array}$ \\
\hline
\end{tabular}


toninérgica (Mechoulam y cols., 1994; ver Tabla 4), aunque, el número de estudios sobre las interacciones cannabinoides/5HT es escaso. Algunos se refieren a los efectos de los cannabinoides sobre la secreción de PRL, que podría ser mediada por alteraciones de la actividad serotoninérgica hipotalámica (Kramer y Ben-David, 1978). Se ha visto que la anandamida puede interaccionar in vitro parcialmente con receptores serotoninérgicos aunque a concentraciones suprafisiológicas (Kimura y cols., 1998). En estudios neurofarmacológicos realizados en modelos de exposición perinatal a cannabinoides en ratas, se han visto alteraciones en el desarrollo de la neurotransmisión serotoninérgica (MolinaHolgado y cols., 1997). Se ha descrito una interacción entre los cannabinoides y el receptor de serotonina $5 \mathrm{HT}_{3}$ (Fan, 1995). Aunque hay indicios de la participación del receptor $\mathrm{CB}_{1}$ en dicha interacción, no se sabe de que forma podría producirse esta participación.

\subsection{Aminoácidos neurotransmisores: GABA y glutamato}

\subsection{1. $G A B A$}

Se han descrito interacciones GABA-cannabinoides en relación al control motor (Romero y cols., 1998a), memoria (Hampson y Deadwyler, 1999) y la regulación neuroendocrina (de Miguel y cols., 1998). Hay receptores $\mathrm{CB}_{1}$ en neuronas GABAérgicas del hipocampo (Tsou y cols., 1998a), y de los ganglios basales (Herkenham y cols., 1991b). En el cerebelo, los receptores $\mathrm{CB}_{1}$ colocalizan con los receptores para GABA en neuronas glutamatérgicas (Pacheco y cols., 1993).

Los endocannabinoides incrementan la acción GABAérgica en el circuito de retroalimentación estriado-substancia nigra, produciendo una disminución de la excitación de las neuronas dopaminérgicas nigroestriatales (Gueudet y col., 1995). Su actuación se produce sobre los receptores $\mathrm{CB}_{1}$ presentes en las neuronas GABAérgicas estriato-eferentes, vía activación de receptores GABA-B. Se pro- duce una inhibición de la recaptación del GABA lo que aumenta el tono GABAérgico en la sustancia nigra (Romero y cols., 1996b) (ver figura 4). El mismo proceso puede ocurrir en otros núcleos receptores de la inervación estriatal, como el globo pálido, lo que estaría relacionados, en este caso, con un aumento de la actividad cataléptica (Maneuf y cols., 1996). Otros estudios han sugerido que los cannabinoides actuarían a nivel de la substancia nigra incrementando la actividad de las neuronas nigrales sin afectar la respuesta a GABA (Tersigni y Rosenberg, 1996) o vía inhibición presináptica de la influencia GABAérgica (a través de la inhibición de canales para $\mathrm{Ca}^{++}$presinápticos) (Chan y cols., 1998).

En relación con las neuronas GABAérgicas hipotalámicas, la administración aguda de $\Delta^{9}$ THC inhibe la secreción de PRL en paralelo a un incremento de las concentraciones de GABA en el hipotálamo medio-basal y en la adenohipófisis, que es mediado por receptores $\mathrm{CB}_{1}$ (de Miguel y cols., 1998). Sin embargo, no hay datos suficientes para afirmar que exista una mediación de las neuronas GABAérgicas. Además, es poco probable que los receptores $C_{1}$, estén localizados sobre las neuronas GABAérgicas tuberoinfundibulares ya que sus cuerpos celulares están en el núcleo arcuado donde no existe señal de ARNm para el receptor $\mathrm{CB}_{1}$ (Mailleux y Vanderhaeghen, 1992).

La presencia de receptores $\mathrm{CB}_{1}$ en interneuronas GABAérgicas hipocampales (Tsou y cols., 1998a), puede estar relacionado con la alteración de la memoria a corto plazo, que se puede producir tras la administración de cannabinoides (presentes en la Cannabis sativa o sintéticos). La estratégica distribución de estos receptores explicaría los importantes efectos producidos por los cannabinoides sobre la memoria y sugiere que los endocannabinoides podrían jugar un importante papel fisiológico en los procesos de la memoria a corto plazo. Se ha propuesto que los receptores $\mathrm{CB}_{1}$ podrían reducir la capacidad de codificar los estímulos de forma que resultaría más difícil retener la información (Hampson y Deadwyler, 1999). Para ello, los cannabinoi- 
des actuarían modificando la actividad GABAérgica que se produce vía activación de receptores GABA-B (Hampson y Deadwyler, 1999), como ocurre en el caso de los efectos motores (Romero y cols., 1996b). La administración de antagonistas del receptor GABA-B atenuó los efectos sobre la memoria causados por cannabinoides sintéticos (Hampson y Deadwyler, 1999).

\subsubsection{Glutamato}

Los cannabinoides sintéticos o naturales alteran la actividad glutamatérgica en neuronas hipocampales, inhibiendo a nivel presináptico la liberación de glutamato. Este efecto es mediado por receptores $\mathrm{CB}_{1}$ acoplados a proteínas Gi (Shen y cols., 1996) y parece estar relacionado con la participación glutamatérgica en la regulación en el hipocampo de los procesos de memoria. También se ha atribuido a los cannabinoides la capacidad de reducir la excitotoxicidad derivada de altos niveles de glutamato (Shen y Thayer, 1998), lo que podría ayudar a retrasar la progresión de las enfermedades neurodegenerativas. En el cerebelo, los receptores $\mathrm{CB}_{1}$ están distribuidos ampliamente en la capa molecular de la corteza cerebelar (Herkenham y cols., 1991a). Se ha descrito que, en secciones de cerebelo de ratas, los cannabinoides inhiben la transmisión sináptica excitatoria, disminuyendo la liberación de glutamato, efecto que fue antagonizado por SR141716A (Levenes y cols., 1998).

La anandamida puede inhibir la neurotransmisión glutamatérgica a nivel del receptor AMPA/kainato en neuronas hipocampales, actuando a nivel presináptico (Shen y cols., 1996). Se ha sugerido que la anandamida interferiría con la liberación de glutamato vía procesos relacionados con la apertura de canales de calcio. También se ha propuesto al 2-araquidonilglicerol como el endocannabinoide activo en este proceso (Stella y cols., 1997).

\subsection{Péptidos opioides}

Los péptidos opioides endógenos interaccionan con los endocannabinoides, compartiendo efectos farmacológicos diversos: hipotermia, sedación, hipotensión, inhibición de la motilidad intestinal y de la actividad locomotora y, sobre todo, antinocicepción (Manzanares y cols., 1999).

Los cannabinoides y los péptidos opioides podrían interaccionar a nivel de sus mecanismos de transducción de señales: inhibición de la adenilato ciclasa/reducción de la producción de AMPc a través de la activación de proteínas Gi. Esto podría explicar la reducción por cannabinoides de la intensidad del síndrome de abstinencia a morfina provocado por naloxona en roedores (Vela y cols., 1995a), así como la potenciación o tolerancia cruzada en relación con los efectos antinociceptivos de ambas sustancias (Thorat y Bhargava, 1994). Sin embargo, esta hipótesis no ha sido demostrada totalmente e, incluso, existen datos contradictorios (para revisión, ver Manzanares y cols., 1999). Exigiría la existencia de una colocalización de receptores para opioides $(\mu, \kappa \circ \delta)$ y para cannabinoides $\left(\mathrm{CB}_{1}\right)$ en las mismas neuronas, un requisito que no siempre se cumple.

Por otro lado, los cannabinoides incrementan la expresión de los genes para los tres tipos de péptidos opioides, POMC, proencefalinas y prodinorfinas, en diversas regiones del cerebro y de la médula espinal. Esto explicaría la capacidad de antagonistas opioides de bloquear los efectos antinociceptivos de los cannabinoides (Reche y cols., 1996) e inducir signos de abstinencia en ratas tolerantes a $\Delta^{9}$-THC (Vela y cols., 1995b). Podría tratarse de un proceso mas general, dado que el incremento en la expresión de péptidos opioides no solo ocurre en áreas relacionadas con la antinocicepción, sino también en otras que lo están con la recompensa cerebral, la regulación de la actividad motora y la regulación neuroendocrina (para revisión, ver Manzanares y cols., 1999). 


\begin{tabular}{|ll|}
\hline $\begin{array}{c}\text { Tabla 5. Efectos de los endocannabinoides y de los cannabinoides derivados } \\
\text { de la Cannabis sativa sobre la actividad de diversos neurotransmisores } \\
\text { durante el desarrollo del cerebro }\end{array}$ \\
\hline Neurotransmisor & $\begin{array}{l}\text { Efectos de los cannabinoides sobre distintos indices neuroquímicos } \\
\text { Dopamina }\end{array}$ \\
\hline $\begin{array}{l}\text { diversos cambios en la expresión del gen de la TH } \\
\text { disminución de la actividad de la TH y del recambio de DA } \\
\text { disminución de la inmunorreactividad para TH } \\
\text { aumento en la densidad de los receptores D1 y D2 } \\
\text { aumento en la producción de DOPAC } \\
\text { tendencia a reducirse la actividad motora } \\
\text { cambios en la respuesta farmacológica a diversas drogas activas sobre la DA }\end{array}$ \\
\hline Serotonina & $\begin{array}{l}\text { disminución de los contenidos de } 5 \text { HT en diversas regiones } \\
\text { aumento de los contenidos de 5HIAA en diversas regiones }\end{array}$ \\
\hline GABA & $\begin{array}{l}\text { mayor respuesta farmacológica a baclofen pero no a muscimol } \\
\text { sin cambios en la eficacia de la activación de los receptores GABA-B } \\
\text { alteración del aprendizaje en algunos tests }\end{array}$ \\
\hline Péptidos opioides & $\begin{array}{l}\text { aumento de las concentraciones de met-encefalina y b-endorfinas en el hipotálamo } \\
\text { aumento en la densidad de receptores } \mu \text {-opioides en las áreas relacionadas con el refuerzo } \\
\text { disminución de la expresión de proencefalina } \\
\text { incremento de la conducta de condicionamiento al sitio para morfina } \\
\text { incremento de la conducta de autoadministración de morfina } \\
\text { reducción de la sensibilidad al dolor } \\
\text { signos de abstinencia inducidos por naloxona }\end{array}$ \\
\hline
\end{tabular}

\section{ENDOCANNABINOIDESY NEUROTRANS- MISORES DURANTE EL DESARROLLO CEREBRAL.}

Algunos neurotransmisores como la DA son especialmente sensibles a los cannabinoides durante el desarrollo cerebral. Probablemente, ésto tiene que ver, en primer lugar, con el posible papel de los endocannabinoides en el desarrollo del cerebro sobre el que podrían ejercer una acción epigenética, y, en segundo lugar, con la función neurotrófica desarrollada por algunos neurotransmisores como la 5HT y, especialmente, la DA. Estos neurotransmisores aparecen tempranamente en el cerebro en desarrollo e, incluso, a veces de forma transitoria para desarrollar un papel específico en la diferenciación neuronal. Existe una larga lista de estudios neurofarmacológicos que demuestran que la exposición peri- natal a cannabinoides altera el desarrollo de la neurotransmisión dopaminérgica, así como de otros neurotransmisores, y de las funciones asociadas a todos ellos (ver Tabla 5). Estos efectos parecen ser la consecuencia de la activación de receptores $\mathrm{CB}_{1}$, los cuales aparecen tempranamente en el cerebro en desarrollo. Se ha demostrado la presencia de "endocannabinoides" y de sus receptores (ARNm, "binding" y activación de mecanismos de transducción de señales) en el cerebro fetal y neonatal (Berrendero y cols., 1998 y 1999). Además, utilizando cultivos de células neuronales o gliales obtenidas de cerebro fetal, se ha demostrado expresión de receptores $\mathrm{CB}_{1}$, activación de proteínas $\mathrm{G}$ y efectos sobre la expresión de ciertos genes (Hernández y cols., 1997 y 1999), que se suman a las observaciones de otros autores sobre el metabolismo de la glucosa (Sánchez y cols., 
1998), movilización de ácido araquidónico (Shivachar y cols., 1996) o expresión de genes tempranos (Bouaboula y cols., 1995). Todo esto permite sugerir que el sistema cannabinoide endógeno debe jugar un papel específico sobre el desarrollo cerebral (para revisión ver Fernández-Ruiz y cols., 1999 y 2000).

\section{BIBLIOGRAFÍA.}

Aceto M.D., Scates S.M., Lowe J.A., Martin B.R. (1995) Cannabinoid precipitated withdrawal by the selective cannabinoid receptor antagonist, SR 141716A. Eur. J. Pharmacol. 282:R1-R2.

Bachur NR., Masek K., Melmon KL., Udenfriend S. (1995) Fatty acid amides of ethanolamine in mammalian tissues J. Biol Chem 240:10191024.

Beltramo M., Stella N., Calignano A., Lin S.Y., Makriyannis A., Piomelli D. (1997) Functional role of high-affinity anandamide transport, as revealed by selective inhibition. Science $\mathbf{2 7 7}$ : 1094-1097.

Ben-Shabat S., Fride E., Sheskin T., Tamiri T., Rhee M.H., Vogel Z., Bisogno T., De Petrocellis L., Di Marzo V., Mechoulam R. (1998) Eur. J. Pharmacol. 353:23-31.

Berrendero F., García L., Hernández M.L., Romero J., Cebeira M., deMiguel R., Ramos J.A., Fernandez-Ruiz J.J., (1998) Localization of mRNA expression and activation of signal transduction mechanisms for cannabinoid receptor in rat brain during fetal development. Development 125:3179-3188.

Berrendero F., Sepe N., Ramos J.A., Di Marzo V., Fernandez-Ruiz J.J. (1999) Analysis of cannabinoid receptor binding and mRNA expression and endogenous cannabinoid contents in the developing rat brain during late gestation and early postnatal period. Synapse 33:181-191.

Bisogno T., Berrendero F., Ambrosino G., Cebeira M., Ramos J.A., Fernandez-Ruiz J.J., Di Marzo V. (1999) Brain regional distribution of endocannabinoids: Implications for their biosynthesis and biological function. Biochem. Biophys. Res. Commun. 256:377-380.

Bornheim L.M., Kim K.Y., Chem B., Correia M.A. (1995) Microsomal cytochrome P-450-media- ted liver and brain anandamide metabolism. Biochem. Pharmacology 50:667-686 .

Bouaboula M., Poinot-Chazel C., Bourrié B., Canat X., Calandra B., Rinaldi-Carmona M., Le Fur G., Casellas P. (1995) Activation of mitogen-activated protein kinases by stimulation of the central cannabinoid receptor CB1. Biochem. J. 312:637-641.

Bouaboula M., Bourrie B., Rinaldi-Carmona M., Shire D., Le Fur G., Casellas P. (1995b) Stimulation of cannabinoid receptor CB1 induces Krox24 expression in human astrocytoma cells. J. Biol. Chem. 270:13973-13980.

Bouaboula M., Poinot Chazel C., Marchand J., Canat X., Bourrie B., Rinaldi-Carmona M., Calandra B., Le Fur G., Casellas P. (1996) Signaling pathway associated with stimulation of CB2 peripheral cannabinoid receptor. Involvement of both mitogen-activated protein kinase and induction of Krox-24 expression. Eur. J. Biochem 237:704-711.

Bouaboula M., Perrachon S., Milligan L., Canat X., Rinaldi-Carmona M., Portier M., Barth F., Calandra B., Pecceu F., Lupker J., Maffrand J.P., Le Fur G., Casellas P. (1997) A selective inverse agonist for central cannabinoid receptor inhibits mitogen-activated protein kinase activation stimulated by insulin or insulin-like growth factor. 1. Evidence for a new model of receptor/ligand interactions. J. Biol. Chem. 272:22330-22339.

Breivogel C.S., Sim C.J., Childers S.R. (1997) Regional differences in cannabinoid receptor/Gprotein coupling in rat brain. J. Pharmacol. Exp. Ther. 282:1632-1642.

Calandra B., Portier M., Kerneis A., Delpech M., Carillon C., Le Fur G., Ferrara P., Shire D. (1999) Dual intracellular signaling pathways mediated by the human cannabinoid CB1 receptor. Eur. J. Pharmacol. 374:245-455.

Calignano A., LaRana G., Giuffrida A., Piomelli D. (1998) Control of pain iniciation by endogenous cannabinoids. Nature 394:277-281.

Chan P.K., Chan S.C., Yung W.H. (1998) Presynaptic inhibition of GABAergic inputs to rat substantia nigra pars reticulata neurones by a cannabinoid agonist. Neuroreport 9:671-675.

Chen J., Paredes W., Li J., Smith D., Lowinson J., Gardner E.L. (1990) D9-Tetrahydrocannabinol produces naloxone-blockable enhancement of presynaptic basal dopamine efflux in nucleus accumbens of concious, freely-moving rats as 
measured by intracerebral microdialysis. Psychopharmacol. 102:156-162.

Cravatt B.F., Giant D.K., Mayfield S.P., Boger D.L., Lerner R.A., Gigula N.B. (1996) Molecular characterization of an enzyme that degrades neuromodulatory fatty-acid amides. Nature. 384:83-87.

Deadwyler S.A., Hampson R.E., Childers S.R. (1995) Functional significance of cannabinoid receptors in brain. pp 205-231. En Pertwee R. (ed) Cannabinoid receptors. Academic Press. London.

De Miguel R., Romero J., Muñoz R.M., García-Gil L., González S., Villanúa M.A., Makriyannis A., Ramos J.A., Fernández-Ruiz J.J. (1998) Effects of cannabinoids on prolactin and gonadotrophin secretion: involvement of changes in hypothalamic GABA inputs. Biochem. Pharmacol. 56:1331-1338.

Derkinren P., Toutant M., Burgaya F., Le Bert M., Siciliano J.C., De Franciscis V., Gelman M., Girault J.A. (1996) Regulation of a neural form of focal adhesion kinase by anandamide. Science 273:1719-1722.

Devane W.A., Dysarz F.A., Johnson M.R., Melvin L.S., Howlett A.C. (1988) Determination and characterization of a cannabinoid receptor in rat brain. Mol Pharmacol. 34:605-613.

Devane W.A., Hanus L., Breuer A., Pertwee R.G., Stevenson L.A., Griffin G., Gibson D., Mandelbaum A., Etinger A., Mechoulam R. (1992) Isolation and structure of a brain constituent that binds to the cannabinoid receptor. Science 258:1946-1949.

Di Marzo V., Fontana A., Cadas H., Schinelli S., Cimino G., Schwartz J.C., Piomelli D. (1994) Formation and inactivation of endogenous cannabinoid anandamide in central neurons. Nature 372:686-691.

Facci L., Dal Toso R., Romanello S., Buriani A., Skaper S.D., Leon A. (1995) Mast cells express a peripheral cannabinoid receptor with differential sensitivity to anandamide and palmitoylethanolamide. Proc. Natl. Acad. Sci. 92:3376-3380.

Fan P. (1995) Cannabinoid agonists inhibit the activation of $5 \mathrm{HT} 3$ receptors in rat nodose ganglion neurons. J. Neurophysiol 73:907-910.

Felder C., Glass M. (1998) Cannabinoid receptors and their endogenous agonists. Ann. Rev. Pharmacol and Toxicol. 38:179-200.
Fernández-Ruiz J.J., Muñoz R.M., Romero J., Villanúa M.A., Makriyannis A., Ramos J.A. (1997) Time-course of the effects of different cannabimimetics on prolactin and gonadotrophin secretion: evidence for the presence of CB1 receptors in hypothalamic structures and their involvement in the effects of cannabimimetics. Biochem. Pharmacol. 53:1919-1927.

Fernández-Ruiz J.J., Berrendero F., Hernández M.L., Romero J. Ramos J.A. (1999) Role of endocannabinoids in brain development. Life Sci. 65:725-736.

Fernández-Ruiz J.J., Berrendero F., Hernández M.L., Ramos J.A. (2000) The endogenous cannabinoid system and brain development. Trends Neurosci. 23:14-20.

French E.D., Dillon K., Wu X. (1997) Cannabinoids excite dopamine neurons in the ventral tegmentum and substantia nigra. Neuroreport 8:649-652

Gaoni Y., Mechoulam R. (1964) Isolation, structure, elucidation and partial synthesis of an active constituent of hashish". J. Am. Chem. Soc. 86:1646-47.

García D.E., Brown S., Hille B., Mackie K. (1998) Protein kinase $\mathrm{C}$ disrupts cannabinoid actions by phosphorylation of the CB1 cannabinoid receptor. J. Neurosci. 18:2834-2841.

Gardner E.L., Paredes W., Smith D., Donner A., Milling C., Cohen D., Morrison D. (1988) Facilitation of brain stimulation reward by D9tetrahydrocannabinol. Psychopharmacol. 96: 142-144.

Gardner E.L. (1992) Cannabinoid interaction with brain reward systems - The Neurobiological basis of cannabinoid abuse. pp. 275-335. En Marijuana/Cannabinoids. Neurobiology and Neurophysiology (eds. L. Murphy, A. Bartke), CRC Press, Boca Raton, FL.

Giuffrida A., Parsons L.H., Kerr T.M., Rodriguez F., Navarro M., Piomelli D. (1999) Dopamine activation of endogenous cannabinoid signaling in dorsal striatum. Nature Neuros. 2:358-363.

Gueudet C., Santucci V., Rinaldi-Carmona M., Soubrie P., Le Fur G. (1995) The CB1 cannabinoid receptor antagonist SR141716A affects $A 9$ dopamine neuronal activity in the rats. Neuroreport 6:1421-1425.

Guzmán M., Fernández-Ruiz J.J., Sánchez C., Velasco G., Ramos J.A. (1995) Effects of anandamide on hepatic fatty acid metabolism. Biochem Pharmacol 50:885-888. 
Guzmán M., Sánchez C. (1999) Effects of cannabinoids on energy metabolism. Life Sci. 65:657664.

Hampson R.E., Deadwyler S.A. (1999) Cannabinoids, hippocampal function and memory. Life Sci. 65:715-723 (1999).

Hansen H.S., Lauritzen L., Strand AM., Vinggaard AM., Frandsen A., Schousboe A. (1997) Characterization of glutamate-induced formation of $\mathrm{N}$ acylphosphatidylethanolamine and $\mathrm{N}$-acylethanolamine in cultured neocortical neurons. J. Neurochem. 69:753-61.

Hanus L., Gopher A., Almog S., Mechoulam R. (1993) Two new unsaturated fatty acids ethanolamides in brain that bind to the cannabinoid receptor. J. Med. Chem 36:3032-3034.

Herkenham M., Lynn A.B., Johnson M.R., Melvin L.S., De Costa B.R., Rice K.C. (1991a) Characterization and localization of cannabinoid receptors in rat brain: a quantitative in vitro autoradiographic study. J. Neurosci. 11:563-583.

Herkenham M., Lynn A.B., de Costa B.R., Richfield E.K. (1991b) Neuronal localization of cannabinoid receptors in the basal ganglia of the rat brain. Brain Res. 547:267-274.

Hernández M.L., García-Gil L., Berrendero F., Ramos J.A., Fernández-Ruiz J.J. (1997) D9Tetrahydrocannabinol increases activity of tyrosine hydroxylase in cultured fetal mesencephalic neurons. J. Mol. Neurosci. 8:83-91.

Hernández M.L., Berrendero F., Suárez I., García-Gi L., Cebeira M., Mackie K., Ramos J.A., Fernández-Ruiz J.J. (1999) Cannabinoid CB1 receptors colocalize with tyrosine hydroxylase in cultured fetal mesencephalic neurons and their activation increases the levels of this enzyme. J. Neurochem. (en prensa).

Hillard C.J., Aucharmpach J.A. (1994) In vitro activation of brain protein kinase $C$ by the cannabinoids. Biochem. Biophys. Acta 1120:163-170.

Hillard C.J., Edgemond W.S., Jarrahian A., Campbell W.A. (1997) Accumulation of $\mathrm{N}$-arachidonoylethanolamine (anandamide) into cerebellar granule cells occurs via facilited diffusion. J. Neurochem 69:631-638.

Hoehe M.R., Caenazzo L., Martínez M.M., Hsieh W.T., Modi W.T., Gershon E.S., Bonner T.I. (1991) Genetic and physical mapping of the human cannabinoid receptor gene to chromosome 6 q14-q15. New Biol. 3:880-885.
Kaminski N.E. (1998) Regulation of the cAMP cascade, gene expression and inmune function by cannabinoid receptors. J. Neuroimmunol 83:124-132.

Kimura T., Ohta T., Watanabe K., Yoshimura H., Yamamoto I. (1998) Anandamide, an endogenous cannabinoid receptors ligand, also interacts with 5-hydroxytryptamine (5-HT) receptor. Biol. Pharm. Bull. 21:224-226.

Kramer J., Ben-David M., (1987) Prolactin supression by (-)-D9-tetrahydrocannabinol (THC): involvement of serotoninergic and dopaminergic pathways. Endocrinology 103:452-458.

Lee M., Yang K.H., Kaminski N.E. (1995) Effects of putative cannabinoid receptor ligands, anandamide and 2-arachidonyl-glycerol, on immune function in B6C3F1 mouse splenocytes. J. Pharm. Exp. Ther. 275:529-536.

Levenes C., Daniel H., Soubrie P., Crepel F. (1998) Cannabinoids decrease excitatory synaptic transmission and impair long-term depression in rat cerebellar Purkinje cells. J. Physiol. (London) 510:867-879.

Maccarrone M., van der Stelt M., Rossi A., Veldink G.A., Vliegenthart F.G., Finazzi A. (1998) Anandamide hydrolysis by human cells in culture and brain. J. Biol. Chem. 273:32332-32339.

Mackie K., Hille B. (1992) Cannabinoids inhibit Ntype calcium channels in neuroblastoma-glioma cells. Proc. Natl Acad. Sci. 89:3825-3829.

Mailleux P., Vanderhaeghen J.J. (1992) Distribution of neuronal cannabinoid receptors in the adult rat brain: a comparative receptor binding radioautography and in situ hybridization hystochemistry. Neuroscience 48:655-668.

Mailleux P., Vanderhaeghem J.J. (1993) Glucocorticoid regulation of cannabinoid receptor messenger RNA levels in rat caudate-putamen. An in situ hybridation study. Neurosci. Let. 156:51-53.

Mailleux P., Verslype M., Preud 'Homme X., Vanderhaeghem J.J. (1994) Activation of multiple transcription factor genes by D9-tetrahydrocannabinol in rat forebrain. Neuroreport 5:1265-1268.

Maneuf Y.P., Crossman A.R., Brotchie J. (1996) Modulation of GABAergic transmission in the globus pallidus by the synthetic cannabinoid WIN 55,212-2. Synapse 22:382-385.

Maneuf Y.P., Brochie J.M. (1997) Paradoxical action of the cannabinoid WIN-55,212-2 in stimulated and basal cyclic AMP accumulation in rat globus pallidus slices. Br. J. Pharmacol 120:1397-1398. 
Manzanares J., Corchero J., Romero J., FernándezRuiz J.J., Ramos J.A., Fuentes J.A. (1999) Pharmacological and biochemical interactions between opioids and cannabinoids. Trends Pharmacol. Sci. 20:287-294.

Martin B.R., Mechoulam R., Razdan R.K. (1999) Discovery and characterization of endogenous cannabinoids. Life Sciences 65:573-595.

Matsuda L.A., Lolait S.J., Brownstein M.J., Young A.C., Bonner T.I. (1990) Structure of a cannabinoid receptor and functional expression of the cloned cDNA. Nature 346:561-564.

Mechoulam R., Hanus L., Martin B.R. (1994) Search for endogenous ligands of the cannabinoid receptors. Biochem. Pharmacol. 48:15371544.

Mechoulam R., Ben-Shabat S., Hanus L., Ligumsky M., Kaminski N.E., Schatz A.R., Gopher A., Almog S., Martin B.R., Compton D.R., Pertwee R.G., Griffin G., Bayewitch M., Barg J., Vogel Z. (1995) Identification of an endogenous 2monoglyceride, present in canine gut, that binds to cannabinoid receptor. Biochem. Pharmacol. 50:83-90.

Molina-Holgado F., Amaro A., González M.I., Alvarez F.J., Leret M.L. (1996) Effects of maternal D9-tetrahydrocannabinol on developing serotonergic system. Eur. J. Pharmacol. 316:39-42.

Molina-Holgado F., Alvarez F., González M.I., Antonio M.T., Leret M.L. (1997) Maternal exposure to D9-tetrahydrocannabinol affects indolamine levels and turnover in adult male and female rat brain regions. Brain Res. Bull. 43:173-178.

Munro S., Thomas K.L., Abu-Shaar M. (1993) Molecular characterization of a peripheral receptor for cannabinoids. Nature 365:61-65.

Navarro M., Fernández-Ruiz J.J., de Miguel R., Hernández M.L., Cebeira M., Ramos J.A. (1993) An acute dose of D9-tetrahydrocannabinol affects behavioral and neurochemical indices of mesolimbic dopaminergic activity. Behav. Brain Res. 57:37-46.

Pacheco M.A., Ward S.J., Childers S.R. (1993) Identification of cannabinoid receptors in cultures of rat cerebellar granule cells. Brain Res. 603:102-110.

Pérez-Reyes M., Bernstein S.H., White W.R., McDonald S.A., Hicks R.E. (1991) Antagonism of marihuana effects by indomethacin. Life Sci. 48:507-515.
Pertwee R.G. (1997) Pharmacoly of cannabinoid CB1 and CB2 receptors. Pharmacol. Ther. 74:129-180.

Pertwee R.G. (1999) Evidence for the presence of CB1 cannabinoid receptors on peripheral neurones and for the existence of neural non-CB1 cannabinoid receptors. Life Sci. 65:597-605.

Reche I., Fuentes J.A., Ruiz-Gayo M. (1996) A role for central cannabinoid and opioid systems in peripheral D9-tetrahydrocannabinol-induced analgesia in mice. Eur. J. Pharmacol. 301:75-81.

Rhee M., Bayewitch M., Avidor-Reiss T., Levy R., Vogel Z. (1998) Cannabinoid receptor activation differentially regulates the various adenylyl cyclase isozymes. J. Neurochem 71:15251534.

Rinaldi-Carmona M., Barth F., Heaulme M., Shire D., Calandra B., Congy C., Martinez S., Marunai J., Neliat G., Caput D., Ferrara P., Soubrie J.C., Le Fur G. (1994) SR141716A, a potent and selective antagonist of the brain cannabinoid receptor. FEBS Lett. 350:240-44.

Rinaldi-Carmona M., Barth F., Millan J., Derocq J.M., Casellas P., Congy C., Oustric D., Sarran M., Bouaboula M., Calandra B., Portier M., Shire D., Breliére J. C., Le Fur G. (1998) SR144528, the first potent and selective antagonist of the CB2 cannabinoid receptor. J. Pharmacol Exp. Ther. 284:644-650.

Rodriguez F., Gorriti M.A., Fernández-Ruiz J.J., Palomo T., Ramos J.A. (1994a) Down- regulation of rat brain cannabinoid binding sites after chronic D9-tetrahydrocannabinol treatment. Pharmacol. Biochem Behavior. 47:33-40.

Rodriguez F., Cebeira M., Ramos J.A., Martín M., Fernández-Ruiz J.J. (1994b) Cannabinoid receptor in rat brain areas: sexual differences, fluctuations during estrous cycle and changes after gonadectomy and sex steroid replacement. Life Science 54:159-170.

Romero J., García L., Ramos J.A., Fernández-Ruiz J.J. (1994) The putative cannabinoid receptor ligand, anandamide, stimulates hypothalamic tyrosine hydroxylase activity and inhibits prolactin release. Neuroend. Lett. 16:159-164.

Romero J., García L., Cebeira M., Zadrozny D., Fernández-Ruiz J.J., Ramos J.A. (1995a) The endogenous cannabinoid receptor ligand, anandamide, inhibits the motor behavior: role of nigrostriatal dopaminergic neurons. Life Sci. 56:2033-2040. 
Romero J., de Miguel R., García-Palomero E., Fernández-Ruiz J.J., Ramos J.A. (1995b) Time-course of the effects of anandamide, the putative endogenous cannabinoid receptor ligand, on extrapyramidal function. Brain Res. 694:223-232.

Romero J., García L., Cebeira M., Fernández-Ruiz J.J., Ramos J.A. (1995c) Changes in rat brain cannabinoid binding sites after acute o chronic exposure to their endogenous agonist, anandamide or to D9-tetrahydrocannabinol. Pharmacol. Biochem Behavior 51:731-737.

Romero J., García-Palomero E., Lin S.Y., Ramos J.A., Makriyannis A., Fernández-Ruiz J.J. (1996a) Extrapyramidal effects of methanandamide, an analog of anandamide, the endogenous CB1 receptor ligand. Life Sci. 58:1249-1257.

Romero J., García-Palomero E., Fernández-Ruiz J.J., Ramos J.A. (1996b) Involvement of GABAB receptors in the motor inhibition produced by agonists of brain cannabinoid receptors Behavioral Pharmacology 7:299-302.

Romero J., García-Palomero E., Castro J.G., GarcíaGil L., Ramos J.A., Fernández-Ruiz J.J. (1997) Effects of chronic exposure to D9-tetrahydrocannabinol on cannabinoid receptor binding and mRNA levels in several rat brain regions. Mol. Brain Res. 46:100-108.

Romero J., de Miguel R., Ramos J.A., FernándezRuiz J.J. (1998a) The activation of cannabinoid receptors in striatonigral GABAergic neurons inhibited GABA uptake. Life Sci. 62:351-363.

Romero J., Wenger T., de Miguel R., Ramos J.A., Fernández-Ruiz J.J. (1998b) Cannabinoid receptor binding did not vary in several hypothalamic nuclei after hypothalamic deafferentation. Life Sci. 63:351-356.

Romero J., Berrendero F., García L., de la Cruz P., Ramos J.A., Fernández-Ruiz J.J. (1998c) Loss of cannabinoid receptor binding and messenger RNA levels and cannabinoid agonist-stimulated [35S]-guanylyl-5'-O-(thio)-triphosphate binding in the basal ganglia of aged rats. Neuroscience 84:1075-1083.

Sagan S., Venance L., Torrens Y., Cordier J., Glowinski J., Giaume C. (1999) Anandamide and WIN 55,212-2 inhibit cyclic AMP formation through G-protein-coupled receptors distinct from CB1 cannabinoid receptors in cultured astrocytes. Eur. J. Neurosci. 11:691-699.

Sánchez C., Galve-Roperh I., Rueda D., Guzmán M. (1998) Involvement of sphingomyelin hydrolysis and the mitogen-activated protein kinase cas- cade in the D9-tetrahydrocannabinol-induced stimulation of glucose metabolism in primary astrocytes. Mol Pharmacol. 54:834-843.

Schmid H.H.O., Schmid P.C., Natarajan V. (1990) Nacylated glycerophospholipid and their derivatives. Progr. Lipid Res. 29:1-43.

Shen M., Piser T.M., Seybold V.S., Thayer A. (1996) Cannabinoid receptor agonists inhibit glutamatergic synaptic transmission in rat hippocampal cultures. J. Neuros. 16:4322-4334 .

Shen M., Thayer S.A. (1998) Cannabinoid receptor agonists protect cultured rat hippocampal neurons from excitotoxicity. Mol. Pharmacol. 54:459-462.

Shire D., Carillon C., Kaghad M., Calandra B., Rinaldi-Carmona M., Le Fur G., Caput D., Ferrara P. (1995). An amino-terminal variant of the central cannabinoid receptor resulting from alternative splicing. J. Biol Chem. 270:3726-3731.

Shivachar A.C., Martin B.R., Ellis E.F. (1996) Anandamide- and D9-tetrahydrocannabinol-evoked arachidonic acid mobilization and blockade by SR 141716A [N-(piperidin-1-yl)-5-(4-chlorophenyl)-1-(2,4-dichlorophenyl)-4-methyl-1 Hpyrazole-3-carboximide hydrochloride]. Biochem. Pharmacol. 51:669-676.

Skaper S.D., Buriani A., Dal Toso R., Petrelli L., Romanello S., Facci L., Leon A. (1996a) Palmitoylethanolamide and cannabinoids, but not anandamide, are protective in a delayed postglutamate paradigm of excitotoxic death in cerebellar granule neurons. Proc. Natl. Acad. Sci. 93:3984-3989.

Skaper S.D., Facci L., Romanello S., Leon A. (1996b) Mast cell activation causes delayed neurodegeneration in mixed hippocampal cultures via the nitric oxide pathway. J. Neurochem. 66:1157-1166.

Stefano G.B., Liu Y., Goligorsky M.S. (1996) Cannabinoid receptors are coupled to nitric oxide release in invertebrate immunocytes, microglia, and human monocytes. J. Biol. Chem. 271:19238-19242.

Stella N., Schweitzer P., Piomelli D. (1997) A second endogenous cannabinoid that modulates longterm potentiation. Nature 388:773-778.

Sugiura T., Kondo S., Sukagawa A., Nakane S., Shinoda A., Ittoh K., Yamashita A., Waku K. (1995) 2-Arachidonoylglycerol: a possible endogenous cannabinoid receptor ligand in brain. Biochem. Biophys. Res. Commun. 215:89-97. 
Tersigni T.J., Rosenberg H.C. (1996) Local pressure application of cannabinoid agonists increases spontaneous activity of rat substantia nigra pars reticulata neurons without affecting response to iontophoretically-applied GABA. Brain Res. 733:184-192.

Thorat S.N., Bhargava H.N. (1994) Evidence for a bidirectional cross-tolerance between morphine and D9-tetrahydrocannabinol in mice. Eur. J. Pharmacol. 260:5-13.

Tsou K., Patrick S., Walker J.M. (1995) Physical withdrawal in rats tolerant to D9-tetrahidrocannabinol precipitated by a cannabinoid receptor antagonist. Eur. J. Pharmacol. 280:R13-R15.

Tsou K., Brown S., Sañudo-Peña M.C., Mackie K., Walker J.M. (1998a) Immunohistochemical distribution of cannabinoid-CB1 receptors in the rat central nervous system. Neuroscience 83:393-411.

Tsou K., Nogueron M.I., Muthian S., Sañudo-Peña M.C., Hillard C.J., Deutsch D.G., Walker J.M. (1998b) Fatty acid amide hydrolase is located preferentially in large neurons in the rat central nervous system as revealed by immunohistochemistry. Neurosci. Lett. 254:137-140.

Twichell W., Brown S., Mackie K. (1997) Cannabinoids inhibit $\mathrm{N}$-and $\mathrm{P} / \mathrm{Q}$-type calcium channels in cultured rat hippocampal neurons. J. Neurophysiol 78:43-50.

Valk P., Verbakel S., Vankan Y., Hol S., Mancham S., Ploemacher R., Mayen A., Lowenberg B., Delwel R. (1997) Anandamide, a natural ligand for the peripheral cannabinoid receptor is a novel synergistic growth factor for hematopoietic cells. Blood 90:1448-1457.

Vela G., Ruiz-Gayo M., Fuentes J.A. (1995a) Anandamide decreases naloxone-precipitated withdrawal signs in mice chronically treated with morphine. Neuropharmacol. 34:665-668.

Vela G., Fuentes J.A., Bonnin A., Fernández-Ruiz J.J., Ruiz-Gayo M. (1995b) Perinatal exposure to D9-tetrahydrocannabinol (D9-THC) leads to changes in opioid-related behavioral patterns in rats. Brain Res. 680:142-147.

Wakamatsu K., Masaki T., Itoh F., Kondo K., Sudo K. (1990) Isolation of fatty acid amide as an angiogenic principle from bovine mesentery. Biochem. Biophysic. Res. Commun 168:423-429.

Wartmann M., Campbell D., Subramaniam A., Burstein S.H., Davis R.J. (1995) The MAP kinase signal transduction pathway is activated by the endogenous cannabinoid anandamide FEBS Letters. 359:133-136.

Westlake T.M., Howlett A.C., Bonner T.I., Matsuda L.A., Herkenham M. (1994) Cannabinoid receptor binding and messenger RNA expression in human brain: an "in vitro" receptor autoradiography and "in situ" hybridation histochemistry study of normal aged and Alzheimer's brains. Neuroscience 63:637-652.

Wickens A.P., Pertwee R.G. (1993) D9-Tetrahydrocannabinol and anandamide enhance the ability of muscimol to induce catalepsy in the globus pallidus of rats. Eur. J. Pharmacol. 250:205208. 